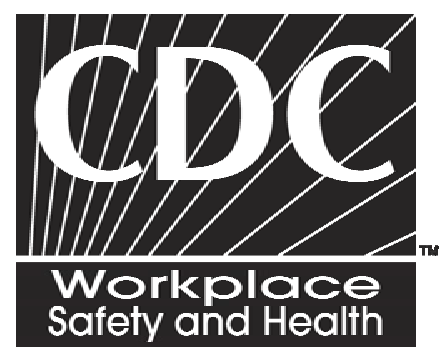

NIOSH HEALTH HAZARD EVALUATION REPORT

HETA \#2003-0146-2976

Genesis Steel Services, Inc. Baltimore, Maryland

\title{
July 2005
}

DEPARTMENT OF HEALTH AND HUMAN SERVICES Centers for Disease Control and Prevention National Institute for Occupational Safety and Health

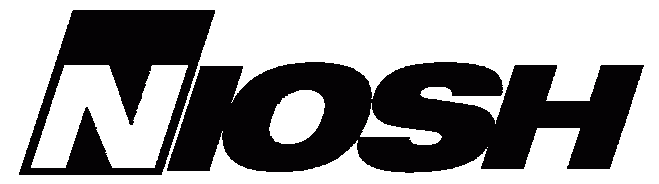




\title{
PREFACE
}

The Hazard Evaluation and Technical Assistance Branch (HETAB) of the National Institute for Occupational Safety and Health (NIOSH) conducts field investigations of possible health hazards in the workplace. These investigations are conducted under the authority of Section 20(a)(6) of the Occupational Safety and Health (OSHA) Act of 1970, 29 U.S.C. 669(a)(6) which authorizes the Secretary of Health and Human Services, following a written request from any employers or authorized representative of employees, to determine whether any substance normally found in the place of employment has potentially toxic effects in such concentrations as used or found.

HETAB also provides, upon request, technical and consultative assistance to federal, state, and local agencies; labor; industry; and other groups or individuals to control occupational health hazards and to prevent related trauma and disease. Mention of company names or products does not constitute endorsement by NIOSH.

\section{ACKNOWLEDGMENTS AND AVAILABILITY OF REPORT}

This report was prepared by Jim Albers, Steve Hudock and Yong-Ku Kong, OSHFB, Division of Applied research and Technology (DART). Field assistance was provided by Dwight Werren (OSHFB). Analytical support was provided by Brian Lowe (OSHFB/DART), Sunil Sudhakaran (OSHFB/DART), and Ed Krieg (CST/DART). Desktop publishing was performed by Juanita Nelson. Review and preparation for printing was provided by Rick Hartle and Ellen Galloway.

Copies of this report have been sent to employee and management representatives at Genesis Steel Services, Inc. and the OSHA Regional Office. This report is not copyrighted and may be freely reproduced. The report may be viewed and printed from the following internet address: http://www.cdc.gov/niosh/hhe. Single copies of this report will be available for a period of three years from the date of this report. To expedite your request, include a self-addressed mailing label along with your written request to:

\author{
NIOSH Publications Office \\ 4676 Columbia Parkway \\ Cincinnati, Ohio 45226 \\ 800-356-4674 \\ or visit the NIOSH web site at: \\ http://www.cdc.gov/niosh/hhe
}

After this time, copies may be purchased from the National Technical Information Service (NTIS) at 5825 Port Royal Road, Springfield, Virginia 22161. Information regarding the NTIS stock number may be obtained from the NIOSH Publications Office at the Cincinnati address.

For the purpose of informing affected employees, copies of this report shall be posted by the employer in a prominent place accessible to the employees for a period of $\mathbf{3 0}$ calendar days. 


\section{Highlights of the NIOSH Health Hazard Evaluation}

\section{Evaluation of NIOSH Health Hazard Evaluation}

NIOSH Investigator evaluated workers' risk of developing back and wrist disorders associated with tying rebar and the possible benefits of using a battery powered tier (BPT) as a substitute for manual tying to prevent upper extremity and low back musculoskeletal disorders.

\section{What NIOSH Did}

- Measured the posture of the dominant wrist and the low back when workers tied rebar with wire using one of three techniques: 1) a pliers, 2) a battery powered tier (BPT), and 3 ) the battery powered tier with an extension handle (BPT+E).

- Made measurements of workers tying rebar on a freeway bridge deck.

- Videotaped workers tying rebar and evaluated the videotape later for trunk posture.

- Talked to reinforcing iron workers to see how they liked the BPT and BPT+E.

\section{What NIOSH Found}

- Manually tying rebar with a pliers involves rapid and repetitive hand and forearm movements associated with increased risk of developing a hand, wrist, or elbow disorder.

- Using the extension handle with the BPT requires the least deep forward bending.

- The risk for developing a hand and wrist musculoskeletal disorder was reduced when the BPT or BPT+E are used.

- Workers supported their upper body weight with their free arm when tying at ground level using the BPT.

\section{What Managers Can Do}

- Minimize the frequency and time employees manually tie rebar using the pliers.

- Provide BPTs to employees when they tie rebar more than 1 hour per day.

- Provide an extension handle for the BPTs for ground level tying.

- Provide employees information describing the signs and symptoms of low back and hand, wrist and elbow disorders.

\section{What the Employees Can Do}

- Minimize the time spent in deep forward bending when tying rebar using the pliers.

- Use the BPT and the extension handle when they are available.

- Report to management any low back or upper limb aches, stiffness, or pain that may be due to work.

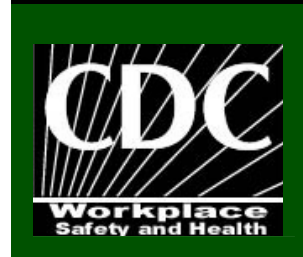

What To Do For More Information: We encourage you to read the full report. If you would like a copy, either ask your health and safety representative to make you a copy or call 1-513-841-4252 and ask for HETA Report 2003-0146-2976\#

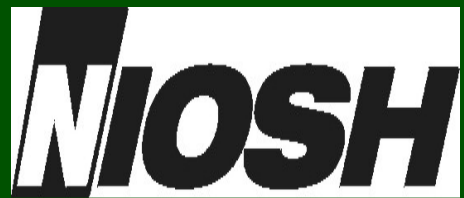




\title{
Health Hazard Evaluation Report 2003-0146-2976 Genesis Steel Services, Inc. Baltimore, Maryland June 2005
}

\author{
Jim Albers, MPH, ClH \\ Steve Hudock, PHD, CSP \\ Yong-Ku Kong, PHD
}

During February 2003, the National Institute for Occupational Safety and Health (NIOSH) received a management request for a Health Hazard Evaluation (HHE) from the Genesis Steel Services, Inc. (GSSI). GSSI requested that NIOSH:

- Evaluate the risk that reinforcing ironworkers have for developing back and hand disorders as a result of hand-tying reinforcement steel on concrete bridge decks and other large concrete slab jobs; and

- Investigate whether the use of reinforcing steel battery powered tying tools can be an effective intervention for the prevention of work-related musculoskeletal disorders (WMSDs) of the upper limbs and back.

In response to the request, NIOSH investigators evaluated GSSI employees' biomechanical loading during rebar tying on a freeway-bridge construction site.

NIOSH investigators measured employees' wrist and forearm movement with goniometers while crew members tied reinforcing steel using three different tying methods. The employees were videotaped and the tape was analyzed to record trunk postures. NIOSH investigators analyzed the data collected and compared the results with criteria used to describe and contrast the levels of hand-wrist and low-back biomechanical loading for GSSI employees for each rebar tying technique used.

Manually tying rebar at ground level using a pliers and wire involved sustained deep trunk bending and rapid, repetitive, and forceful hand-wrist and forearm movements that would require limits on the amount of time workers can safely do the work. Using a battery powered rebar tying tool significantly reduced the use of rapid and repetitive hand-wrist and forearm movements and freed one hand to support the trunk during tying. Adding an extension handle to the battery powered rebar tying tool allowed workers to tie rebar standing erect

Keywords: NAICS 23412 (SIC 1622), ergonomics, reinforcement steel, bridge deck construction, workrelated musculoskeletal disorders, low back, hand-wrist 


\section{Table of Contents}

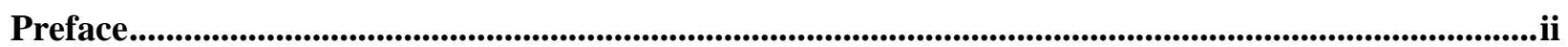

Acknowledgments and Availability of Report..................................................................................................ii

Highlights of the Health Hazard Evaluation ...............................................................................................iii

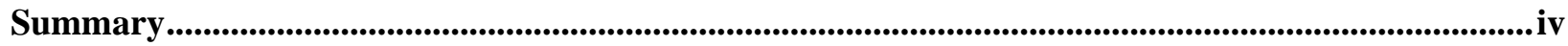

Introduction ............................................................................................................................... 1

Background .......................................................................................................................................... 1

Springfield Interchange Freeway Bridge............................................................................................... 1

Installing and Fastening Rebar for the Bridge.......................................................................................... 1

Methods....................................................................................................................................................

Data collection ........................................................................................................................................ 2

Data Analyses ......................................................................................................................................

Goniometric data ...........................................................................................................................................

Positional data

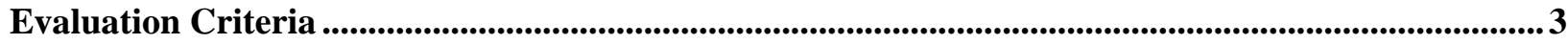

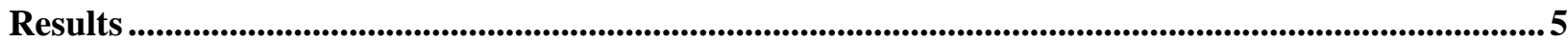

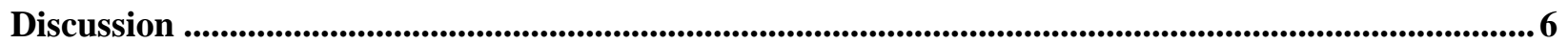

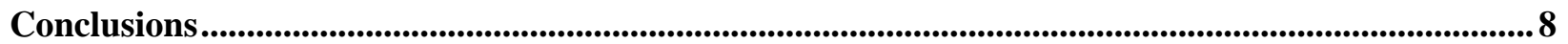

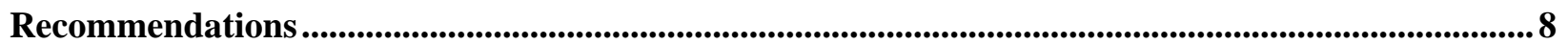

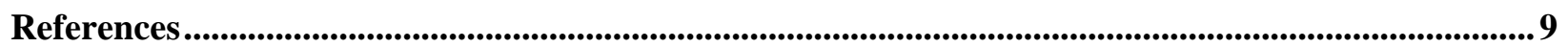





\section{INTRODUCTION}

In February 2003, the National Institute for Occupational Safety and Health (NIOSH) received a request for a Health Hazard Evaluation (HHE) from the vice-president of the Genesis Steel Service, Inc (GSSI). GSSI, a construction reinforcing and structural steel contractor in Baltimore, MD, GSSI asked NIOSH to do the following:

- Evaluate the risk that GSSI reinforcing ironworkers have for developing back and hand musculoskeletal disorders as a result of hand-tying reinforcement steel on concrete bridge decks, and

- Investigate whether the use of a battery powered tier (BPT) for rebar tying can be an effective intervention for the prevention of work-related musculoskeletal disorders (WMSDs) of the upper extremities and back.

In response to the request, NIOSH investigators conducted a field investigation of GSSI employees' exposures to biomechanical loading when tying rebar for the concrete deck of an elevated freeway bridge in Springfield, VA. The investigation was conducted on October 27-30, 2003.

\section{BACKGROUND}

Genesis Steel Service, Inc. is a minority owned construction specialty subcontractor providing structural and reinforcing steel services for new construction projects in the greater BaltimoreDistrict of Columbia metropolitan area. The distribution of GSSI's work is approximately $60 \%$ concrete reinforcement, 25\% structural (bridge and buildings < 4 stories), and 15\% miscellaneous metals, including ornamental. GSSI does not operate a fabrication shop and reinforcing steel used on projects is predominantly pre-cut and pre-formed.
At the time of the HHE request, GSSI employed 100 ironworkers (IWs). Around 40\% of the IWs employed by GSSI were minority workers - 20\% African-American and 20\% Hispanic. GSSI estimated that for $2 / 3$ of the Hispanic workers English is their second language. The IWs are members of the International Association of Bridge, Ornamental, and Reinforcing Iron Workers. GSSI estimated that $25-30 \%$ of the IWs employed at the time of the study had been employed by the contractor since 1988. Genesis' IWs tend to specialize in structural or reinforcing work, and most reinforcing ironworkers (RIW), also known as 'rodmen', work exclusively on concrete reinforcing jobs.

\section{Springfield Interchange Freeway Bridge}

As a subcontractor on the Springfield Interchange Improvement Project, GSSI installed reinforcing steel bars for the concrete deck of the bridge connecting westbound I-495 traffic to the southbound I-95 interstate highway. The bridge is approximately one mile long by 60 feet wide. GSSI employees were responsible for placing and tying the steel bars used to reinforce the concrete deck and walls of the bridge. An estimated 2.2 million wire ties were made on the bridge to secure the rebar at a rate of 7 wire ties per square foot $\left(\mathrm{ft}^{2}\right)$ for the bridge. For most of the project, weather permitting, GSSI IWs worked a 5 day and 40 hour work week. The amount of rebar placed and tied on a given day depended on several factors, including the number of workers on the job, the environmental conditions, and the pace of the work preceding rebar installation.

\section{Installing and Fastening Rebar for the Bridge}

Before pouring the concrete deck that will be the surface of the bridge, steel reinforcing bars (aka rebar) must be placed inside the concrete forms. The rebar is used to reinforce and increase the tensile strength (i.e., bending and stretching) of the concrete in the deck and sidewalls. Two rebar 'mats' were placed one above the other inside the concrete form over the full length of 
the bridge. Each mat consisted of a series of bars placed perpendicular to each other and spaced about seven (7) inches on-center. The bottom mat was kept above the metal decking using wire supports (aka chairs). Chairs were used to separate the top mat from the bottom mat. The rebar are tied together to prevent the bars from shifting when the concrete mixture is poured into the form, although the ties do not add strength to the bridge.

The specifications for the job, common for freeway bridge decks in the Unites States, required tying $50 \%$ of the intersecting rebar on the bottom mat and $100 \%$ of the intersections on the top mat. GSSI employees used two techniques to tie the intersecting rebar together, including: 1) pliers and spool of wire and 2) the battery operated RB392 rebar tier (MAX USA Corp., Garden City, New York) (Figure 1). The BPT tier was used most frequently to make the 'snap' or simple ties used to keep the rebar from shifting. Pliers were used when more secure ties (i.e., 'saddle' or 'figure 8') were necessary to frame the sidewalls of the bridge deck or make the first ties for each mat (Figure 2).

Traditional tying (Figure 3) required the use of two hands - one to use the pliers to pull, wrap, twist, and cut the wire and the other to pull and push the wire. Only one hand was necessary to operate the BPT (Figure 4). Both techniques required frequent and sustained deep trunk bending (aka stooping) ( $>90^{\circ}$ trunk inclination) to tie the rebar.

NIOSH introduced a commercially available extension handle developed for use with the BPT (Figure 5 and 6). This was the third rebar tying technique used during the investigation.

\section{METHODS}

GSSI employees were directed to tie the rebar placed for the bottom mat using three different tying techniques: 1) pliers; 2) the RB392 BPT and 3) the BPT with an extension handle $(\mathrm{BPT}+\mathrm{E})$. All employees were familiar with the first two techniques and used each on the site. NIOSH brought the extension handle to the site and none of the employees had previously used the device. Participants were encouraged, but not required, to use the extension before measurements were made.

GSSI had purchased the BPTs approximately 2 years prior to the study in part to reduce employees' exposures to biomechanical loading related to tying using pliers. The power tier still required deep forward bending when tying at deck level, but workers now used one hand to hold the tier and the other to support their upper body while tying.

The investigation was conducted to answer the following questions:

1. How does the use of a battery powered rebar tier (MAX USA RB392) affect the biomechanical loading of the hand-wrist and/or of the low back?

2. How does the use of an adjustable extension handle with the battery powered rebar tier (MAX USA RB392) affect the biomechanical loading of the hand-wrist and/or low back?

3. How does the use of the battery powered rebar tier (MAX USA RB392) with and without the adjustable handle affect the productivity of rebar tying?

\section{Data collection}

Each worker tied rebar for about 30 minutes using the: 1) pliers; 2) BPT; and 3) BPT+E. A twin-axis goniometer (Biometrics SG Series) and torsiometer (Biometrics Q110) were used to measure the dominant wrist motion and position (aka posture) in the flexion/extension, ulnar/radial, and pronation/supination planes (Figure 7) during tying. ${ }^{1}$

Observational methods were used to record the position of the trunk during tying and the number of ties each worker made. This consisted of videotaping each worker from three different angles so that the trunk could be later viewed from both the side and front.

Each worker was asked to describe the physical effort they used with their hand-wrist and lowback on a scale from 0 ('nothing at all') to 10 
('extremely strong') when using the three tying methods. ${ }^{2}$ Prior to conducting the study, the 10point scale was translated into Spanish by a NIOSH contractor.

Personal information and work history was obtained using self administered questionnaires available in English and Spanish.

\section{Data Analyses}

\section{Goniometric data}

The goniometric data were converted to readable files using proprietary Biometrics Ltd. management and analysis software. Statistical analysis, including summary and inferential statistics, was conducted using SAS ${ }^{\circledR}$ Institute software.

\section{Positional data}

Video tape was analyzed using the Multimedia Video Task Analysis (MVTA ${ }^{\mathrm{TM}}$ ) software program, which allowed the analyst to run video tape through the computer. ${ }^{3}$ The analyst recorded the frequency and duration of the trunk posture angles and the time required to tie rebar for each of the three tying techniques.

Analysts used the computer-based 3-D Static Strength Prediction Program ${ }^{\mathrm{TM}}$ to estimate the pressure (compressive forces) on the spinal disc between the fifth lumbar vertebrae and the first sacral vertebrae (aka L5/S1 spinal disc) during rebar tying in stooped postures. ${ }^{4}$ Disc pressure is known to vary depending on the amount and type (e.g., forward, sideward, twisting) of bending.

\section{Evaluation CRITERIA}

Overexertion injuries and musculoskeletal disorders, such as low back pain, tendinitis, and carpal tunnel syndrome, are often associated with job tasks that include:

1. Repetitive, stereotyped movement about the joints;

2. Forceful manual exertions;

3. Lifting, pushing, and pulling;
4. Awkward and/or static body positions;

5. Direct pressure on nerves and soft tissues;

6. Work in cold environments;

7. Exposure to whole-body or segmental vibration; or

8. Work-related psychosocial factors, such as high job demand, low decision latitude, and monotonous activity, etc.

The risk of injury appears to increase as the intensity and duration of exposures to the risk factors increases and the recovery time (i.e., rest time) decreases. Individual characteristics (e.g., age, gender, weight, fitness) are seen as "contributing and modifying influences in the development of pain and disability and in the transition from acute to chronic pain.",

The preferred method for preventing and controlling work-related musculoskeletal disorders (WMSDs) is to reduce or eliminate exposure to the risk factors. The most effective way to do this is to design jobs, workstations, tools, and other equipment to match the physiological, anatomical, and psychological characteristics and capabilities of the worker. Under these conditions, exposures to task factors considered potentially hazardous will be reduced or eliminated.

The following criteria were used to evaluate the biomechanical loading of GSSI employees' low back and upper limbs during rebar tying tasks on the Springfield Interchange Improvement Project:

1. the American Conference of Governmental Industrial Hygienists (ACGIH ${ }^{\mathrm{TM}}$ ) Hand Activity Level (HAL) Threshold Limit Value (TLV) ${ }^{\mathrm{TM}}, 6$

2. recommendations for acceptable hand-wrist motion (e.g., velocity and acceleration) to prevent wrist cumulative trauma disorders (CTD), ${ }^{7}$

3. the Michigan 3-Dimensional Static Strength Prediction Program ${ }^{\mathrm{TM}}$ to estimate the compressive and shear forces on the L5/S1 spinal disc, ${ }^{4}$

4. the Evaluation of Static Working Postures, International Organization for Standardization (ISO) $11226,{ }^{9}$ and 
5. risk assessment of spinal disease as a result of cumulative physical work load on the lumbar spine. ${ }^{10}$

\section{$\underline{\text { ACGIH }^{\mathrm{TM}} \text { Hand Activity Level TLV }}$}

The ACGIH ${ }^{\mathrm{TM}}$ Hand Activity Level (HAL) ${ }^{5}$ $\mathrm{TLV}^{\mathrm{TM}}$ is based on epidemiological, psychophysical, and biomechanical studies and is applied to "mono-task" jobs performed for four hours or more per day. (A mono-task job involves performing a similar set of motions or exertions repeatedly such as working on an assembly line or using a keyboard for transcription.) The HAL is based on the frequency of hand exertions and the duty cycle (distribution of work and recovery periods). The HAL can be determined by a trained observer or calculated using information on the frequency of exertions and the work/recovery ratio. Peak force is normalized on a scale of 0 to 10 , corresponding to $0 \%$ to $100 \%$ of the applicable population reference strength. Peak force can be determined with ratings by a trained observer, ratings using subjective exertion scales (i.e., Borg 10 point perceived effort scale) $)^{2}$, or measured using instrumentation such as strain gauges. Peak force requirements can be normalized by dividing the force required to perform the job by the strength capability of the work population for that activity. The total exposure is characterized in terms of average hand activity level and peak hand force.

\section{Hand-Wrist Motion Guidelines}

Marras and Schoenmarklin studied the relationship between wrist movement, including the angle, repetition, velocity, and acceleration levels, and the risk of developing a CTD. ${ }^{7}$ The study found that high wrist and forearm motion (i.e., angular velocity and angular acceleration) during an 8-hour day were significantly associated with risk of developing an upper extremity CTD. Non-neutral wrist position (aka posture) alone was not associated with an increased risk of developing CTDs. Mean wrist acceleration levels associated with high and low CTD risk in the radial/ulnar, flexion/extension, and pronation/supination planes were, respectively, 494 and 301 angular degrees/second ${ }^{2}\left(\mathrm{~d} / \mathrm{s}^{2}\right), 824$ and $494 \mathrm{~d} / \mathrm{s}^{2}$, and 1824 and $1222 \mathrm{~d} / \mathrm{s}^{2}$. In follow-up analysis of the data, wrist acceleration in the flexion/extension plane was determined to be the best predictor of a hand/wrist CTD. ${ }^{8}$

\section{3-D Static Strength Prediction Program}

The Michigan 3-Dimensional Static Strength Prediction Program $^{\mathrm{TM}} \quad$ (3DSSPP $^{\mathrm{TM}}$ ) is a computerized model which can be used to evaluate the physical demands of a prescribed job. ${ }^{4}$ Typical inputs to the model are the magnitude and direction of forces at the hands, angles of body segments, and worker characteristics. The model calculates forces (i.e., moments) on the joints of the body and estimates the percentage of the workforce able to sustain the inputted loads. Compressive and shear forces for the L5/S1 disc are calculated. The program allows the analyst to estimate the compressive forces acting on the spine relative to the revised NIOSH lifting equation. ${ }^{11}$. In order to prevent low back disorders, NIOSH recommends L5/S1 disc compression force never exceed 3400 Newtons $(\mathrm{N})$ during any single job activity ( $1 \mathrm{~N}=0.225$ pound-force).

The 3DSSPP ${ }^{\text {тм }}$ can be used to evaluate the biomechanical demands of an existing task or to predict the physical demands of a task that is being designed or modified. The joint angles for the program's mannequin were set to represent postures used during rebar tying and estimate the forces exerted on the L5/S1 spinal disc.

\section{$\underline{\text { ISO Evaluation of Static Work Postures }}$}

The ISO developed the consensus standard titled Ergonomics - Evaluation of Static Working Postures (ISO 11226-2000). ${ }^{9}$ ISO 11226 was written to control pain, fatigue and disorders of the musculoskeletal system that may result from the use of non-neutral body postures for long durations without sufficient recovery time. The standard describes acceptable trunk postures and maximum acceptable holding times for potentially harmful postures. 


\section{Cumulative spinal loading and back} disease

Seidler et al investigated the relationship between the cumulative (e.g., added over time) forces on the lumbar section of the back and symptomatic spinal disease, e.g., spondylosis of the lumbar spine. ${ }^{12}$ Specifically, the study compared the stress (i.e., forces) over time on the lumbar spine due to lifting, carrying, and extreme forward flexion $\left(>90^{\circ}\right)$ with the occurrence of back disease (i.e., osteochondrosis or spondylosis) diagnosed using $\mathrm{x}$-rays. The authors reported significantly more spinal disease in the group of workers with the higher cumulative physical stress on the back compared with workers with less back stress. The risk of back disease also increased with the amount of physical force applied to the L5/S1 spinal disc.

\section{RESULTS}

\section{Summary}

Manually tying rebar at ground level using pliers and wire involved sustained deep trunk bending and rapid and repetitive hand and wrist movements. Using a BPT significantly reduced the use of rapid and repetitive hand-wrist and forearm movements characteristic of tying with the pliers, and freed one hand to support the weight of the trunk during tying. Adding an extension handle to the BPT allowed workers to tie rebar standing erect. The results show that manually tying rebar using a pliers involves greater risk of developing a low back WMSD than tying with either the BPT or BPT+E. The study indicates that tying with the BPT $+\mathrm{E}$ also involves less risk of developing an upper limb WMSD.

\section{Demographics}

All eight GSSI employees (six Hispanic, two Caucasian) installing rebar on the freeway bridge agreed to participate in the study. Participant mean age was 37 years old and mean height, weight and body mass index (BMI) were, respectively 69 inches, 184 lbs., and 27.4 BMI (Table 1). Table 2 shows participants' mean time working as a rodbuster, employed by GSSI, and working on the study job site. Participants reported tying rebar using a pliers and using a BPT 8.1 hours/week and 6.1 hours/week, respectively. One worker reported a back injury occurring during the previous 12 months that affected his work. No injuries occurring during the previous 12 months were reported by the remaining seven workers.

\section{Electro-goniometric analyses}

\section{Calibration}

The calibration results for the electrogoniometers demonstrated that the wrist position measurements were accurate and consistent.

\section{Wrist and Forearm Movements}

Wrist mean velocity and mean acceleration were higher during pliers tying than BPT or BPT+E tying. Differences between the pliers and the $\mathrm{BPT}$ or BPT $+\mathrm{E}$ rates were significantly different (Tables 3 and 4). Mean wrist velocities measured in the flexion/extension and ulnar/radial planes during pliers tying exceeded velocities associated with high and low risks of developing a CTD (Figure 8). ${ }^{7}$ The low CTD risk level was exceeded in the ulnar/radial plane using each of the three tying techniques. Operating the BPT resulted in a mean wrist velocity in one plane (ulnar/radial) exceeding the level associated with a high CTD risk.

Figure 9 shows that workers' mean wrist acceleration levels measured during pliers tying exceeded levels found to be associated with (a) high CTD risk in the flexion/extension (i.e., $824 \mathrm{~d} / \mathrm{s}^{2}$ ) and ulnar/radial (i.e., $494 \mathrm{~d} / \mathrm{s}^{2}$ ) planes and (b) low CTD risk in the pronation/supination plane (i.e., $1222 \mathrm{~d} / \mathrm{s}^{2}$ ). Use of the BPT exceeded acceleration levels related to low CTD risk level in the ulnar/radial plane (i.e., $\left.301 \mathrm{~d} / \mathrm{s}^{2}\right)^{7}$

\section{Borg Perceived Effort}

Five workers completed the perceived effort questionnaire. Participants reported the lowest 'low back' effort when using the BPT+E (1.2 on the 10 point Borg scale), followed by 2.8 for the 
BPT and 5.8 for the pliers. The lowest handwrist effort was reported for the BPT (2.8) and the BPT+E and pliers were, respectively, 5.0 and 5.2. (Table 5)

\section{Observational analyses}

\section{ACGIH Hand Activity Level TLVTM}

ACGIH HAL-TLV ${ }^{\text {TM }}$ scores were calculated using the workers' perceived effort scores ${ }^{2}$ (i.e., mean, low and high) for each tying technique. Using the mean scores, the HAL-TLV ${ }^{\mathrm{TM}}(0.78)$ would be greatly exceeded at 2.5 when a pliers was used and slightly exceeded at 0.83 when an BPT+E (0.83) was used for 4 hours or more each day. Use of the BPT alone would not exceed the HAL-TLV ${ }^{\mathrm{TM}}$. (Table 6)

\section{Trunk Positions}

Workers were observed tying rebar with severe trunk bending $\left(\geq 90^{\circ}\right) 94 \%$ of the time when using the pliers and $93 \%$ of the time when using the BPT (Table 7). With the BPT $+\mathrm{E}$ workers tied rebar using neutral trunk positions $\left(<15^{\circ}\right.$ flexion) $83 \%$ of the time and moderate forward flexion $\left(16^{\circ}-30^{\circ}\right) 16 \%$ of the tying time with the extension attached to the power tier.

ISO 11226 recommends that working trunk postures not exceed $60^{\circ}$ of forward bending at any time. Observed trunk postures used during pliers and BPT rebar tying greatly exceeded the ISO 11226 recommendations.

When using the BPT, all workers used their free hand to support the weight of their torso, e.g., resting the hand/forearm on the knee/thigh, $90 \%$ of the time when they tied at ground level. (Table 8) [Note: Workers use two hands to tie using the pliers, while only one hand is necessary using the BPT or BPT+E.]

\section{Other}

\section{$\underline{\text { Cumulative trunk loading }}$}

Using the 3D Static Strength Prediction Program $^{\mathrm{TM}}$ (3DSSPP) $^{4}$, compressive and shear forces acting on the L5/S1disc were estimated to be between $1500 \mathrm{~N}$ to $2850 \mathrm{~N}$ during two-hand rebar tying using the pliers without lateral bending or trunk rotation. (Table 9) Lateral bending ( $25^{\circ}$ left or right) increased both total and shear compression forces when the trunk inclination did not change. Highest shear forces were $501 \mathrm{~N}$ and were recorded at the deepest trunk inclination $\left(-125^{\circ}\right)$ and $25^{\circ}$ lateral bending. Although these forces do not exceed the NIOSH revised lifting guideline (3400 N), the postures must be sustained for several hours each day increasing the cumulative force over many years of activity.

Cumulative forces on the L5/S1 were calculated (Figure 10/Table 10) for rebar tying (average 2 and 4 hours duration/day) and carrying $20 \mathrm{~kg}$ (average 1 hour/day) in front of or beside the body for one, five, and ten years. ${ }^{12}$ Figure 11 shows that the estimated cumulative forces resulted in 2.6 (95\% CI 1.2 - 5.7) and 6.0 (95\% CI 2.7 - 13.4) times greater risk (odds ratios) of developing spinal disease, respectively, after 5 years and 10 years work-exposure. ${ }^{12}$

With the trunk fully flexed, e.g., tying rebar at ground level, the muscles that normally support the spinal column become ineffective and the ligaments take over. ${ }^{13}$ When the lumbar spine becomes stretched out there is a greater potential for damage to the spinal discs. ${ }^{13},{ }^{14}$

\section{Productivity}

Tying with the BPT or BPT+E is faster than using the pliers. The mean number of ties per 2.5 minutes completed using the pliers, BPT, and BPT + E, respectively was: 42,84 , and 52 . (Table 11) Tying times were significantly different for the three techniques when compared to each other.

\section{Discussion}

\section{Risks Associated with Pliers Tying}

Both the ACGIHTM HAL-TLV ${ }^{\mathrm{TM}}$ and the CTD risk estimates developed by Marras and 
Schoenmarklin ${ }^{8}$ assume exposure occurs, respectively, for $\geq 4$ hours and 8 hours each day. Reinforcing ironworkers (RIWs) reported tying rebar for about 16 hours per week using the pliers or BPT. Tying rebar using the pliers for 4 or more hours each day exceeded the ACGIH ${ }^{\mathrm{TM}}$ HAL-TLV ${ }^{\text {TM }}$ by 3.2 times. Using the BPT+E for 4 hours or more each day slightly exceeds the HAL-TLVTM.

During pliers tying, wrist motion (i.e., mean velocity and acceleration) in the flexion/extension and ulnar/radial planes was about twice as fast as the motion associated with both low and high CTD risk reported by Marras and Schoenmarklin. ${ }^{7}$ The upper limb CTD risk assessment they conducted was for an 8-hours work day. RIWs who do not continuously tie rebar with a pliers for 8 hours may not exceed these parameters.

However, pliers tying requires rapid wrist movement in all three planes of motion in combination with hand forces necessary to pull, twist, and cut the wire. Marras and Schoenmarklin ${ }^{7}$ did not describe the combined effect of rapid motion in multiple planes and, therefore, the CTD risk levels reported may underestimate actual risk when rapid motions are required in all three planes.

The frequency and duration of extreme trunk flexion using the pliers increases RIWs' exposure to risk factors for lumbar spine disease after 5-10 years of tying in a stooped posture and put them at greater risk of developing a low back disorder.

The results of the study clearly show that manually tying rebar using a pliers exposes workers to serious risk factors for developing WMSDs of low back and the upper limbs.

\section{Tying Using the BPT and BPT+E}

\section{Hand-Wrist}

Use of the BPT resulted in mean hand-activity level scores below the ACGIH HAL- TLVTM. The $\mathrm{BPT}+\mathrm{E}$ resulted in a mean hand-activity level slightly higher than the TLVTM. This difference can be explained by the higher "perceived effort" scores RIWs gave the BPT+E on the Borg ${ }^{2}$ questionnaire. Unlike the BPT, workers did not have experience using the extension prior to the study. Use of the extension does increase the distance of the hand to the tying location, and possibly reduces control of the tool during placement. Perhaps more importantly, however, positioning and holding the BPT+E away from the body results in higher forces on the hand, arm, and shoulder due to the larger moment. These factors likely increased the "perceived effort" scores during BPT+E use and could be addressed with training.

There was no significant difference between the wrist movement (i.e., velocity and acceleration) when comparing the use of the BPT and BPT+E. $\mathrm{Vi}$ described an increase in productivity for the $\mathrm{BPT}+\mathrm{E}$ comparable to the BPT in a study of union RIWs in Ontario, Canada, who had experience using the extension before the study began. ${ }^{15}$

\section{Low Back}

Use of the BPT+E resulted in the least forward bending during rebar tying. Although the BPT tying trunk positions were not significantly different from pliers tying positions, it is reasonable to assume there is less loading on the lumbar spine. The BPT only requires the use of one hand to tie rebar and all workers were observed using the free hand to support their upper body weight during the majority of the time they were observed tying with the BPT. The use of the hand or arm to support the upper body should reduce the compressive forces applied to the lumbar spine. Participants appear to have confirmed this when they reported significantly less perceived effort for the low back using the BPT+E than the pliers (2.8 for the $\mathrm{BPT}+\mathrm{E}$ and 5.8 for the pliers), despite the similar posture.

\section{Other Activities}


NIOSH analyzed only rebar tying during this study, although reinforcing ironworkers' perform additional job activities that require "maximum muscle force to lift, push, pull, or carry objects."16 For example, in addition to lifting and carrying rebar, workers must also separate individual rebar from the bundles transported to the immediate work area. Rebar transported in bundles can become intertwined, which makes the separation of individual rebar lengths difficult. Workers were observed separating rebar using sudden (i.e., jerking) muscle forces - often in stooped and asymmetrical postures- to separate individual rebar from the bundles.

RIWs' manual material handling activities can comprise a significant percentage of work time. Forde $^{17}$ reported "(m)anual material handling $(\mathrm{MMH})$ activities (lifting, lowering, pushing, pulling, dragging, carrying, holding, forceful motions) were observed $22 \%$ and $32 \%$ of the observed time", respectively, for reinforcing ironworkers building caisson cages and the deck and sides of a freeway access tunnel. If these additional activities had been evaluated during the study, the estimates would be higher and indicate greater risk of developing a back musculoskeletal disorder.

\section{Study Limitations}

There are three limitations of this study. First, participants' time using the extension handle (BPT+E) was measured in minutes, rather than hours. Subsequently, most, if not all, participants had insufficient time to become accustomed to using the extension $(\mathrm{BPT}+\mathrm{E})$. The wrist, elbow, and shoulder can be subjected to larger moments when the tool is positioned and held further from the body. This unfamiliarity may explain some participants higher hand-wrist perceived effort ratings.

Second, the study was not conducted in a manner that could determine the real productivity differences among the three tying techniques. Using the BPT nearly doubled the number of ties completed during the analysis periods, while the $\mathrm{BPT}+\mathrm{E}$ resulted in a slight increase. The observation time, however, was too short to consider possible non-productive time related to using the BPT, such as the additional cost of charging BPT batteries (using gasoline powered generator) on the construction site and potential productivity loss due to changing batteries and BPT mechanical failure, i.e., wire jam. Despite this shortcoming, GSSI ironworkers and management representatives expressed confidence that the MAX USA RB392 power tier increased workers' productivity.

\section{CONCLUSIONS}

1. Manually tying rebar using a pliers exceeded the ACGIH ${ }^{\mathrm{TM}}$ HAL-TLV ${ }^{\mathrm{TM}}$ and wrist velocity.

2. Measured mean wrist velocity and acceleration rates were high in all planes of motion during pliers tying.

3. Tying rebar using the BPT significantly reduced hand and wrist movements that can cause upper limb WMSDs. Deep forward bending was still necessary to tie the rebar, but the 'free' arm supported the weight of the trunk, reducing forces on the L5/S1 disc.

4. Tying rebar using the BPT+E eliminated the sustained deep forward bending required when tying with the pliers and BPT. Wrist movement was significantly lower in all three planes of motion using the BPT+E. Some participants, however, reported hand-wrist effort similar to using the pliers, resulting in a mean hand-activity level score slightly higher than the ACGIH HAL TLVTM.

5. Worker productivity increased when the $\mathrm{BPT}$ or $\mathrm{BPT}+\mathrm{E}$ were used during the study.

\section{RECOMMENDATIONS}

1. Provide battery powered rebar tiers with extension handles whenever reinforcing 
ironworkers tie rebar placed at ground level, i.e., bridge and freeway deck, concrete slab, etc.

2. Provide training to workers who will use the extension handle so that they will be able to correctly adjust the height of the handle and limit the distance they extend the BPT $+\mathrm{E}$ during tying.

3. Encourage reinforcing ironworkers to use the extension for the battery powered tier when they tie rebar at ground level.

4. Provide ironworkers information to enable them to identify the early signs and symptoms of low back and upper extremity musculoskeletal disorders.

5. Future research should be conducted to characterize the following aspects of tying reinforcing steel:

(a) the types of reinforced concrete construction that would benefit from the use of power tiers;

(b) the optimal design of an extension handle for power rebar tiers; and

(c) reinforcing ironworkers biomechanical loading, especially to the back and shoulders, during rebar manual material handling.

\section{REFERENCES}

1 Biometric [2003]. Management and Analysis, Version 3.0. Biometrics, Ltd., Cwmfelinfach, Gwent, United Kingdom

2 Borg, G. [1982] A category scale with ratio properties for intermodal and interindividual comparisons. In: Geissler, H.G. and Petzold, P. (Eds.), Psychophysical judgment and the process of perception. Berlin: VEB Deutscher Verlag der Wissenschaften.

3 UW-Madison [2001] User's Manual for Multimedia Video Task Analysis TM (MVTATM). Madison, WI: Ergonomics Analysis and Design Research Consortium, University of Wisconsin-Madison.
4 University of Michigan, Center for Ergonomics [2001] 3D Static Strength Prediction ProgramTM Version 4.3. Ann Arbor, MI: University of Michigan Center for Ergonomics.

5 NRC/IOM [2001] Musculoskeletal disorders and the workplace: low back and upper extremities. Panel on musculoskeletal disorders and the workplace. Commission on Behavioural and Social Sciences and Education. Washington DC: National Academy Press.

6 ACGIH [2001] Hand Activity Level Threshold Limit Value. TLV/BEI Documentation. Cincinnati, $\mathrm{OH}$ : American Conference of Governmental Industrial Hygienists.

7 Marras WS, Schoenmarklin RW [1993] Wrist motions in industry. Ergonomics 36 (4), 342351.

8 Schoenmarklin RW, Marras WS, Leurgans SE (1994) "Industrial Wrist Motions and Risk of Cumulative Trauma Disorders in Industry," Ergonomics, 37(9), 1449-1459.

9 ISO/CD 11226 [1995] Ergonomics-Evaluation of Working Postures International Organization for Standardization. Geneva, Switzerland.

10 Seidler A, Bolm-Audorff U, Heiskel H, Henkel N, Roth-Küver B, Kaiser U, Bickeböller R, Willingstorfer WJ, Beck W, Elsner G [2001] The role of cumulative physical work load in lumbar spine disease: risk factors for lumbar osteochondrosis and spondylosis associated with chronic complaints. Occup Environ Medicine 58:735-746.

11 Waters TR, Putz-Anderson V, Garg A [1993] Revised NIOSH equation for the design and evaluation of manual lifting tasks. Ergonomics 36 (7) 749-776.

12 Seidler A, Bolm-Audorff U, Heiskel H, Henkel N, Roth-Küver B, Kaiser U, Bickeböller R, Willingstorfer WJ, Beck W, Elsner G [2001] The role of cumulative physical work load in lumbar spine disease: risk factors for lumbar osteochondrosis and spondylosis associated with 
chronic complaints. Occup Environ Medicine 58:735-746

13 Pope MH, Goh KL, Magnusson ML [2002] Spine ergonomics. Annu. Rev. Biomed. Eng. 2002. 4:49-68.

14 Solomonow M, Baratta RV, Banks A, Fruedenberger C, Zhou HE [2003] Flexionrelaxation response to static lumbar flexion in males. Clinical Biomechanics 18: 273-279.

15 Vi P, Schneider S [2005]. Promoting Early Return to Pre-Injury Job Using a Rebar-Tying Machine. J. Occup. Environ. Hyg. 2:D34-D37.
16 Occupational Information Network [2004] Reinforcing iron and rebar workers (472171.00). Occupational Information Network, O*Net Online. http://online.onetcenter.org/ Date accessed December 2004.

17 Forde M. [2002] Reinforcing Ironwork: PATH (Posture, Activity, Tools, Handling) Analysis, Technical Report T-61. Construction Occupational Health Program, Department of Work Environment, University of Massachusetts Lowell, Lowell, MA. http://www.uml.edu/Dept/WE/COHP Date accessed December 2004. 
Figure 1

MAX-USA RB-392 Power rebar tier (BPT)

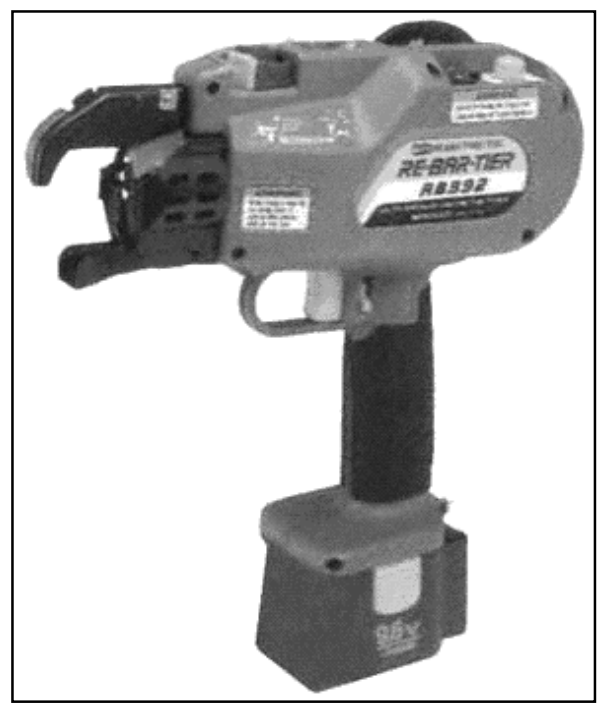

RB-392 Specifications

Max Wraps per Tie

Tying Speed

3

Max Rebar Size (in)

Wire Gauge

Second

Ties per Coil of Wire

$3 / 4$ to $1-1 / 2$

Ties per Battery Charge

21

$180-210$

8000

Voltage

$9.6 \mathrm{DC}$

Weight

4.6 lbs. 
Figure 2

Ties used to secure rebar together

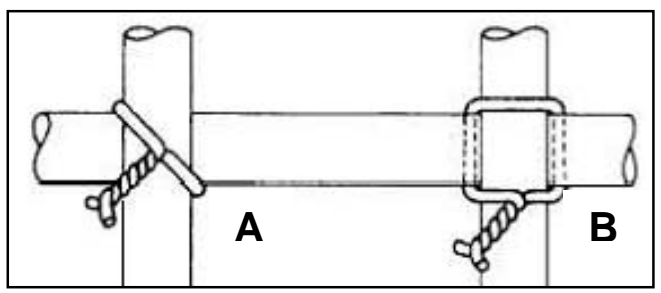
A Snap or simple tie (similar to tie made using power rebar tier, except the power tier wraps wire around bars 3 times)
B Saddle tie


Figure 3

Rebar tying using pliers and tie-wire

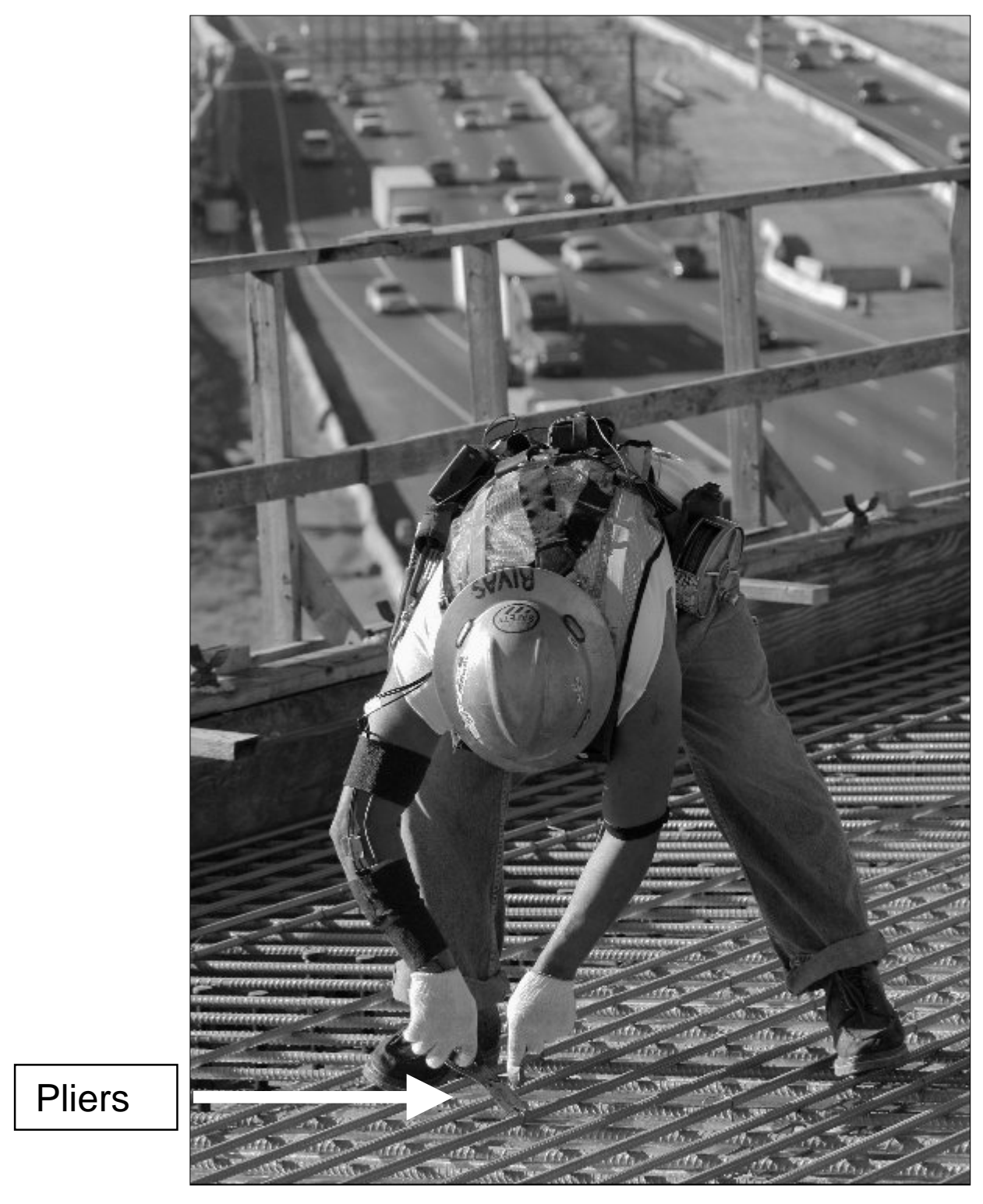


Figure 4

Rebar tying using MAX-USA RB392 battery powered rebar tier

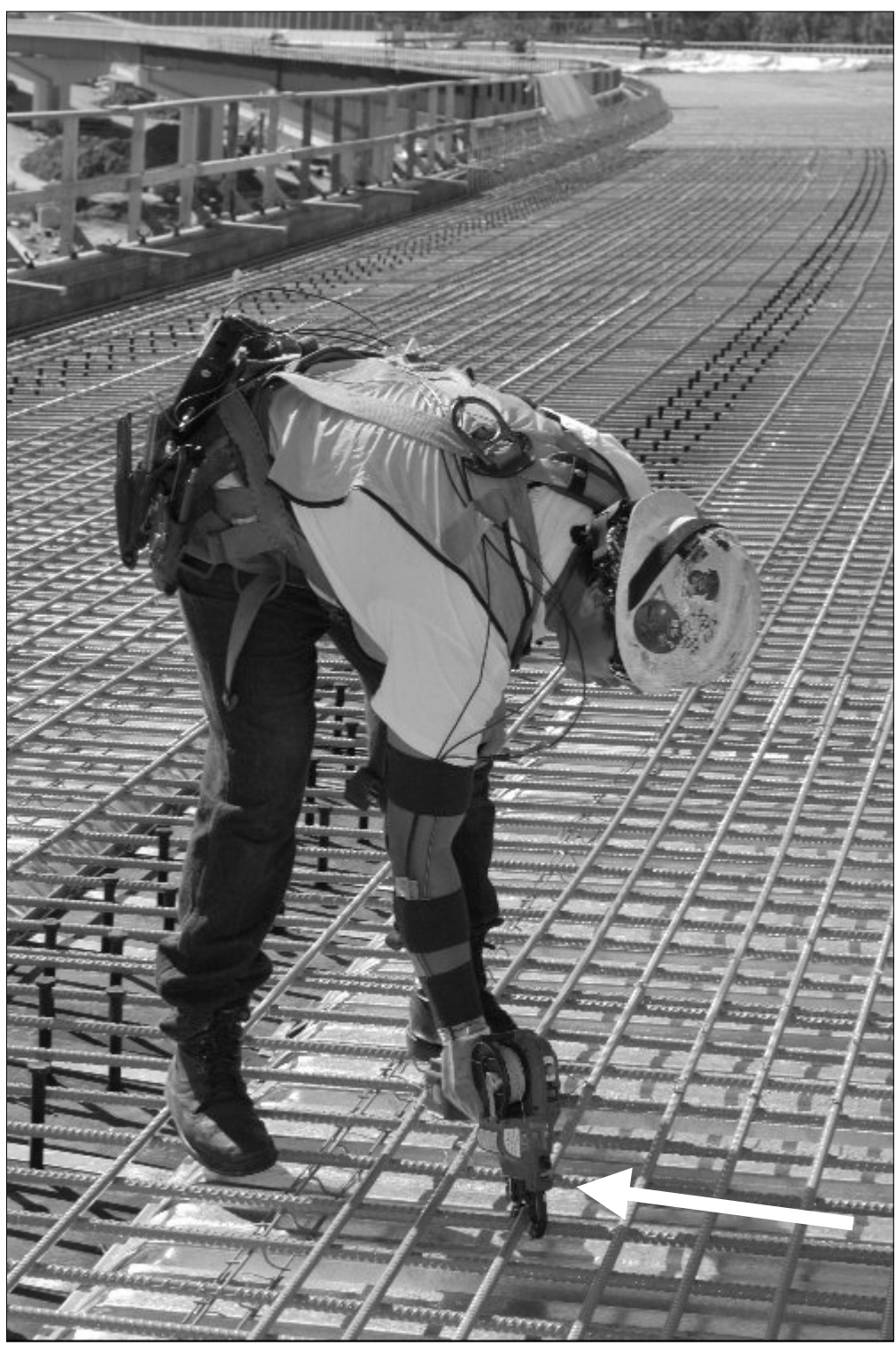

Battery powered tier 
Figure 5

MAX-USA RB-392 Battery powered tier with adjustable extension (BPT+E)

(plan to use image from manufacturer)

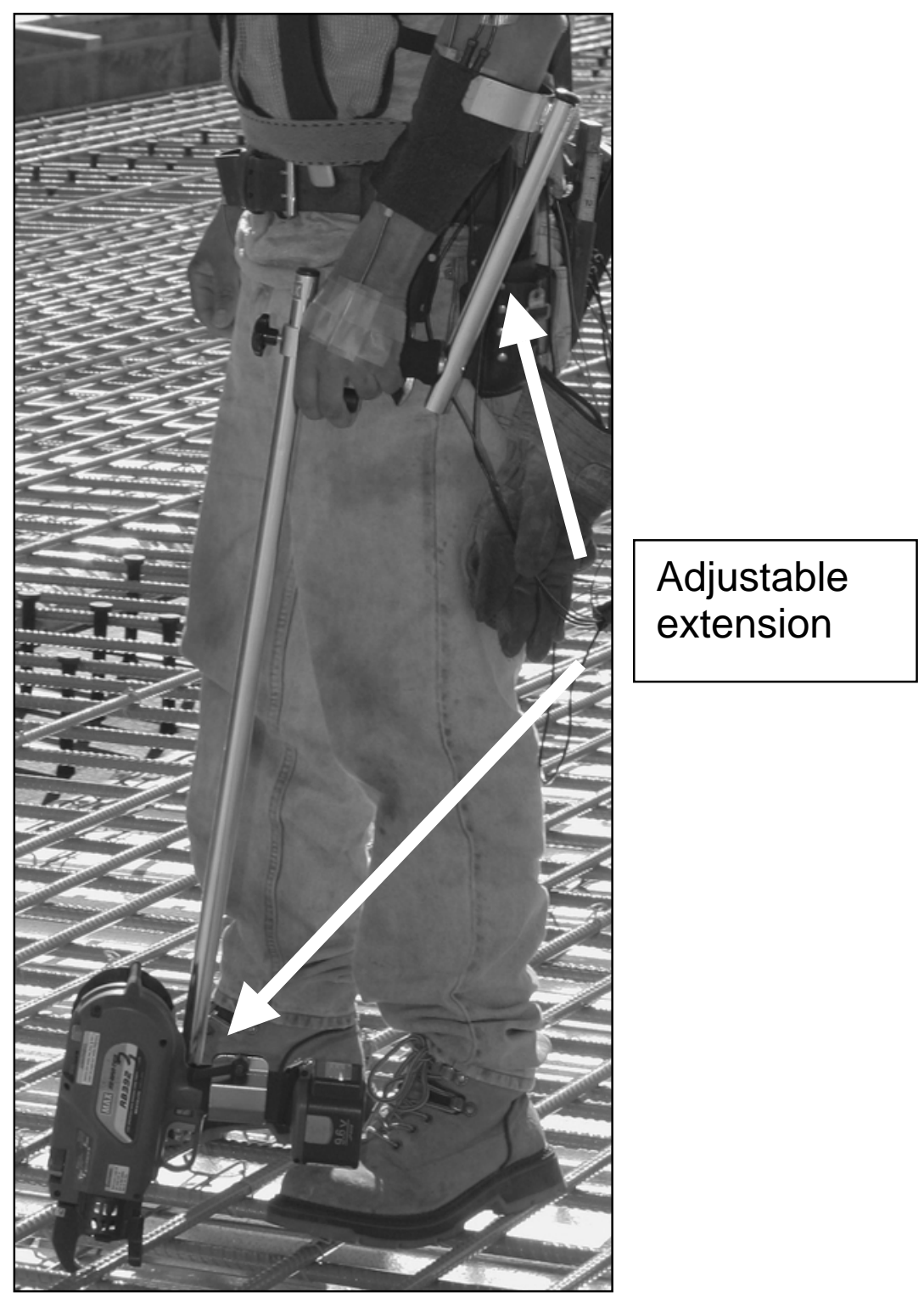


Figure 6

Rebar tying using MAX-USA RB392 power rebar tier with adjustable extension handle

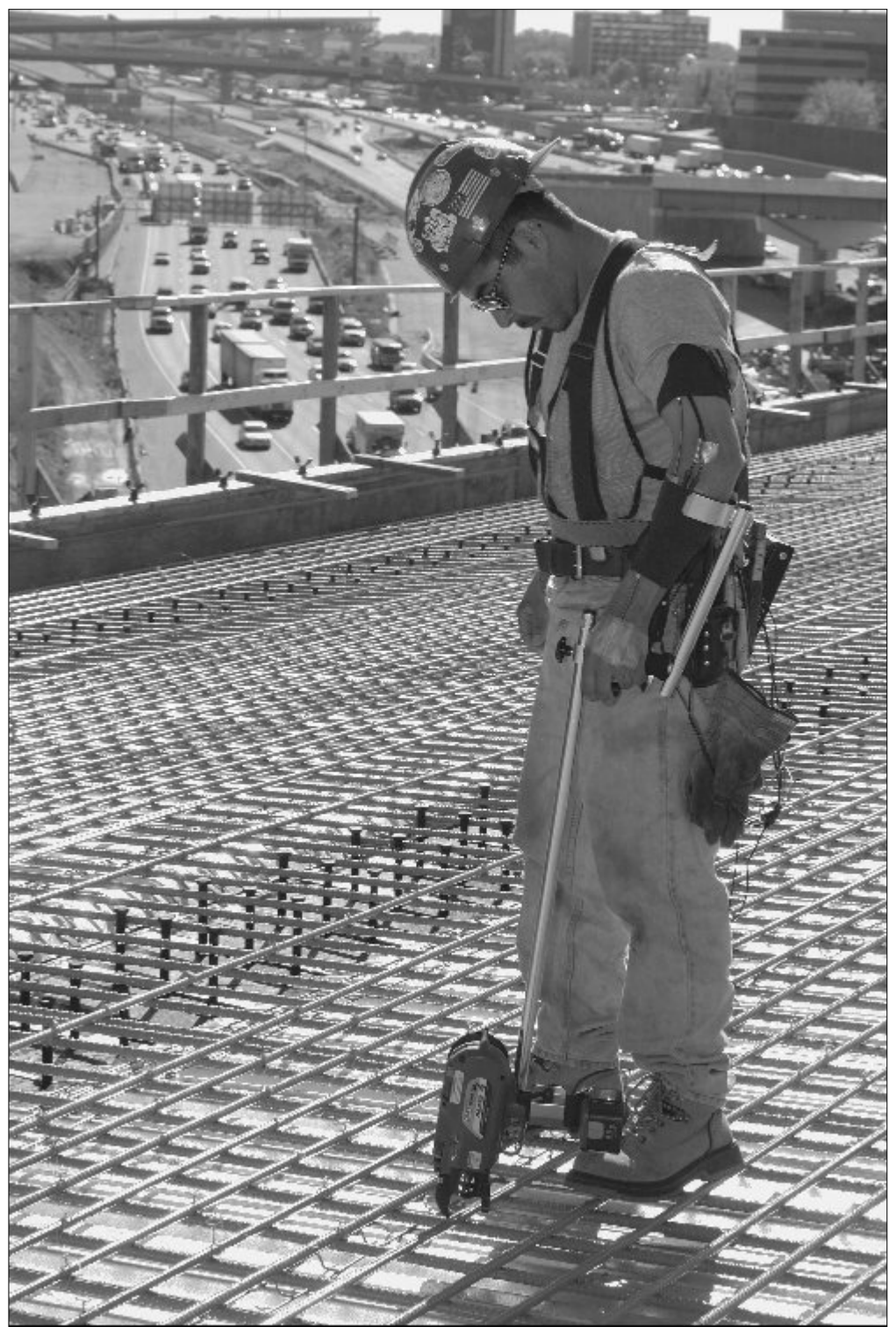


Figure 7

Wrist, hand and arm position/movement planes

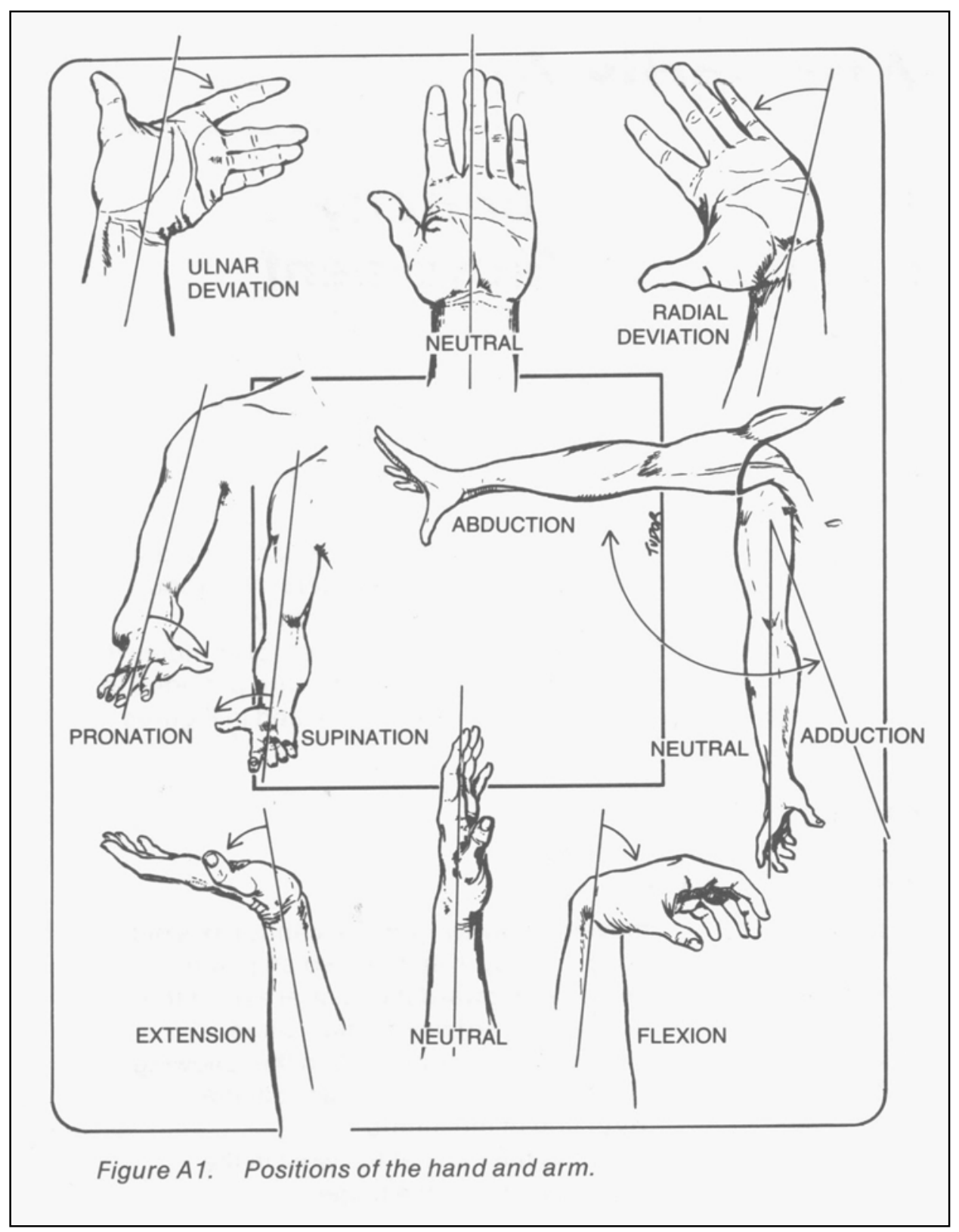


Figure 8

Measured Wrist Velocity during Rebar Tying

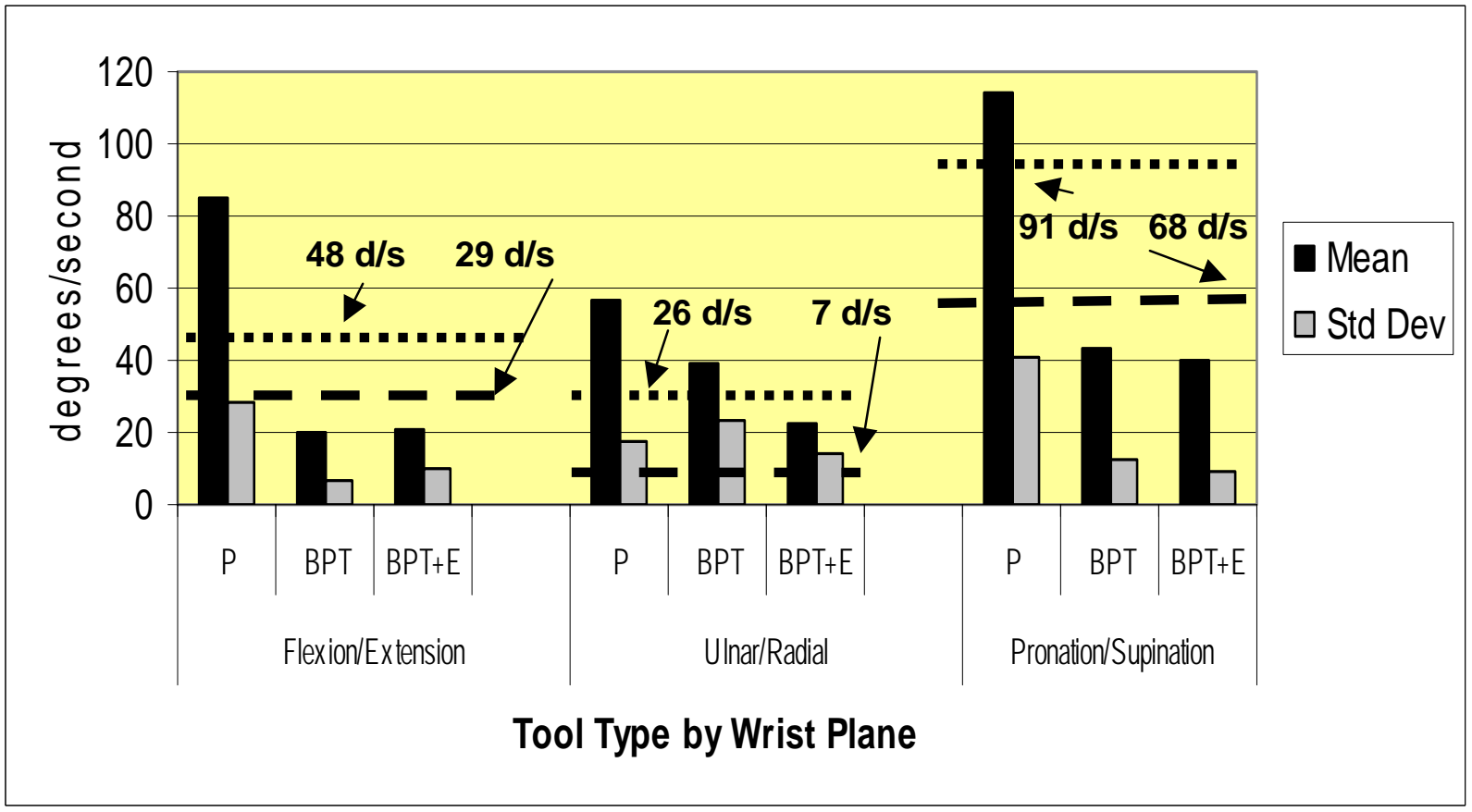

Mean High CTD Risk .............. Mean Low CTD Risk $\mathrm{P}=$ Pliers; $\mathrm{BPT}=$ Battery powered tier; $\mathrm{BPT}+\mathrm{E}=\mathrm{BPT}+$ extension

Wrist acceleration mean and standard deviations measured in three planes (flexion/extension, ulnar/radial \& pronation/supination) during rebar tying and mean high and low CTD risk acceleration rates. ${ }^{7}$ 
Figure 9

Measured Wrist Acceleration during Rebar Tying

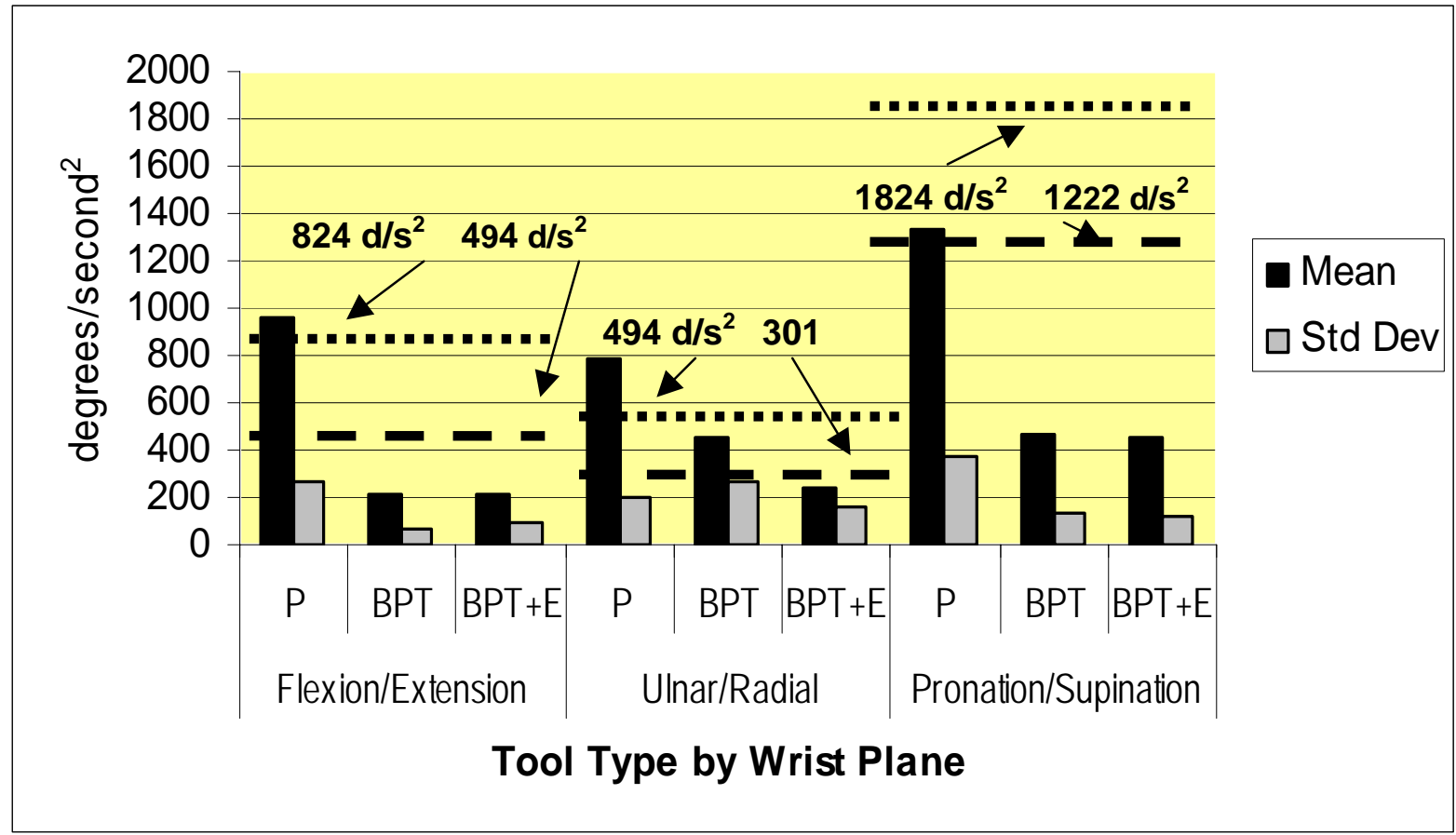

Mean High CTD Risk

Mean Low CTD Risk

$\mathrm{P}=$ Pliers; $\mathrm{BPT}=$ Battery powered tier; $\mathrm{BPT}+\mathrm{E}=\mathrm{BPT}+$ extension

Wrist acceleration mean and standard deviations measured in three planes (flexion/extension, ulnar/radial \& pronation/supination) during rebar tying and mean high and low CTD risk acceleration rates. ${ }^{7}$ 


\section{Figure 10}

Calculation of one-year cumulative load on $\mathrm{L} 5 / \mathrm{S} 1^{12}$ :

Assumptions: Rodman works 180 days per year tying rebar with pliers an average 4 hours per day and carries materials, i.e., rebar, weighing $20 \mathrm{~kg}$ an average 1 hour per day. Extreme forward bending involved in tying rebar at $-(\mathrm{a}),-105^{\circ}$ (b) and $-115^{\circ}$ (c) $90^{\circ}$. (Table 16) Force on lumbar spine from carrying $20 \mathrm{~kg}$ load in front or beside the body equals $2700 \mathrm{~N}$ (Seidler et al, 2001).

DAYS $\sqrt{\mathbf{8 h} * \sum_{\mathbf{i}} \mathbf{F}_{\mathbf{i}} * \mathbf{t}_{\mathbf{i}}} \quad$ Days = working days/year; $\mathrm{t}_{\mathrm{i}}=$ average daily duration of activity (h)

(a)

$\begin{array}{rlrl}1 \mathrm{yr} & = & 180 \sqrt{8 \mathrm{~h} *\left(1721^{2} \mathrm{~N}^{2} * 4 \mathrm{~h}\right)+\left(2700^{2} \mathrm{~N}^{2} * 1\right)} & \\ 5 \mathrm{yr} & & & =1.8 \times 10^{6} \mathrm{Nh} \\ 10 \mathrm{yr} & = & & =9.1 \times 10^{6} \mathrm{Nh} \\ & & =18.2 \times 10^{6} \mathrm{Nh}\end{array}$

(b)

$1 \mathrm{yr}=$

$5 \mathrm{yr}=$

$10 \mathrm{yr}=$

$180 \sqrt{8 \mathrm{~h} *\left(2093^{2} \mathrm{~N}^{2} * 4 \mathrm{~h}\right)+\left(2700^{2} \mathrm{~N}^{2} * 1 \mathrm{~h}\right)}$

$=2.2 \times 10^{6} \mathrm{Nh}$

$=10.9 \times 10^{6} \mathrm{Nh}$

$=21.8 \times 10^{6} \mathrm{Nh}$

(c)

$1 \mathrm{yr}=$

$5 \mathrm{yr}=$

$=2.7 \times 10^{6} \mathrm{Nh}$

$10 \mathrm{yr}=$

$\begin{aligned} 180 \sqrt{8 \mathrm{~h} *\left(2642^{2} \mathrm{~N}^{2} * 4 \mathrm{~h}\right)+\left(2700^{2} \mathrm{~N}^{2} * 1 \mathrm{~h}\right)} & =2.7 \times 10^{6} \mathrm{Nh} \\ & =13.7 \times 10^{6} \mathrm{Nh} \\ & =27.3 \times 10^{6} \mathrm{Nh}\end{aligned}$


Figure 11

Estimated $^{a}$ Cumulative L5/S1 Spinal Disc Loading During Rebar Tying and Carrying ${ }^{b}$ and Risk of Developing Spinal Disease with Chronic Complaints ${ }^{12}$

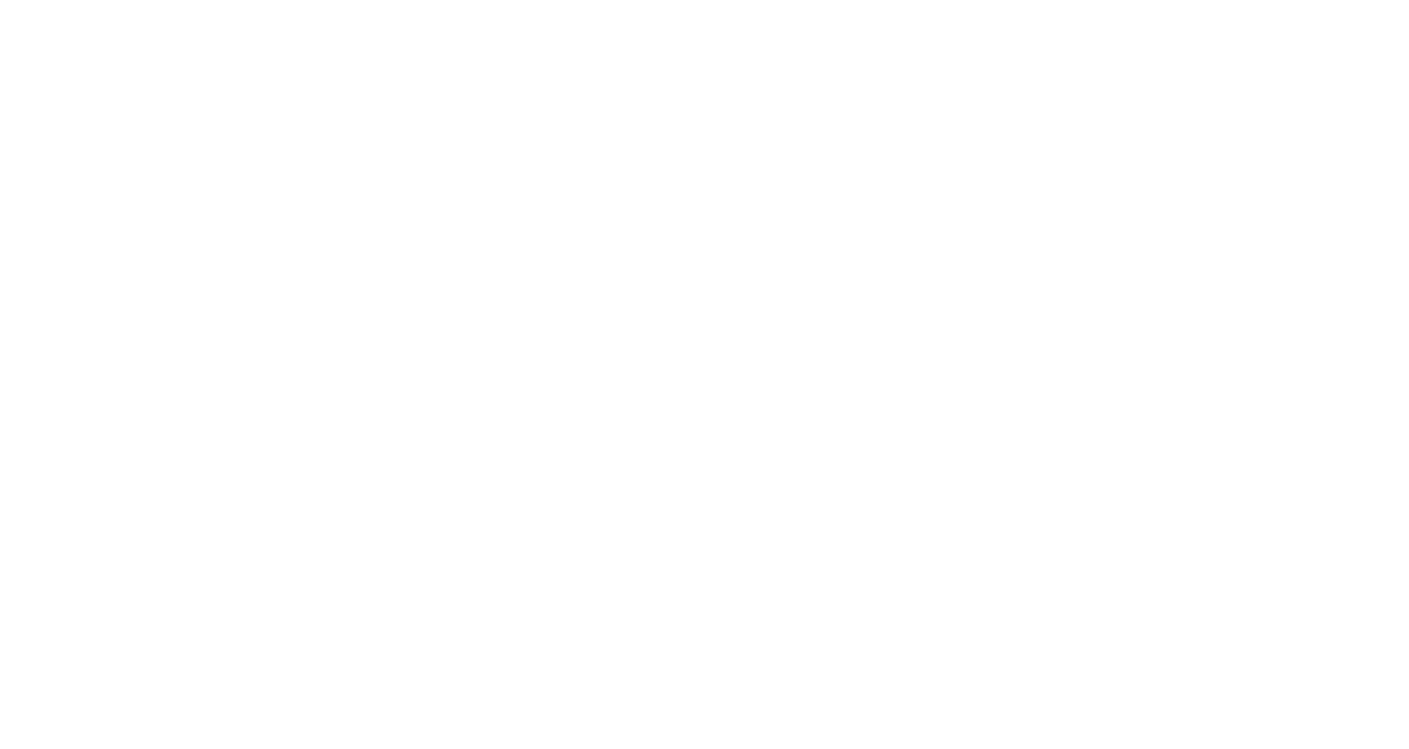

${ }^{\text {a }}$ See equation in Figure $10 .^{12}$

${ }^{\mathrm{b}}$ See Table 19 for estimated spinal loading during tying and carrying.

${ }^{\mathrm{c}}$ Risk of developing lumbar spondylosis with chronic complaints with or without disc herniation $\geq$ Odds Ratio (OR) $=2.6$ (95\% CI 1.2-5.7).

${ }^{\mathrm{d}}$ Risk of developing lumbar spondylosis with chronic complaints with or without disc herniation $\geq$ Odds Ratio (OR) = 6.0 (95\% CI 2.7-13.4). 
Table 1

Anthropometrics of Subjects

\begin{tabular}{cccc} 
Age & Ht. (in.) & Wt. (lb.) & BMI $^{1}$ \\
\hline 42 & 71 & 185 & 25.8 \\
\hline 33 & 66 & 160 & 25.8 \\
\hline 44 & 71 & 210 & 29.3 \\
\hline 40 & 70 & 210 & 29.3 \\
\hline 37 & 67 & 160 & 25.1 \\
\hline 29 & 68 & 190 & 28.9 \\
\hline 30 & 70 & 185 & 26.5 \\
\hline 43 & 65 & 170 & 28.3 \\
\hline $37(6)$ & $69(2.2)$ & $184(18.5)$ & 27.4 \\
\end{tabular}

${ }^{1}$ Body mass index (BMI) calculated using CDC BMI calculator. Accessed on 1029-04. http://www.cdc.gov/nccdphp/dnpa/bmi/calc-bmi.htm.

Table 2

Ironworker Work History (months)

Mean SD Min Max

\begin{tabular}{lrrrr}
\hline Time tying rebar & 124 & 96.4 & 29 & 298 \\
\hline Time with current employer & 38 & 37.7 & 18 & 136 \\
\hline Time on current job site & 16 & 12.6 & 0 & 32 \\
\hline
\end{tabular}




\section{Table 3}

Comparison of Mean Wrist Velocity Postures by Rebar Tying Method (Chi Square Difference of Least Squares Means)

\begin{tabular}{lrrr} 
Plane & Pliers vs. BPT $^{1}$ & Pliers vs. $^{\text {BPT }+E^{2}}$ & BPT vs BPT+E $^{-}$ \\
\hline Flexion/Extension & $<0.0001$ & $<0.0001$ & NS \\
\hline Ulnar/Radial & $\mathrm{NS}$ & $<0.05$ & $\mathrm{NS}$ \\
\hline Supination/Pronation & $<0.0001$ & 0.0001 & $\mathrm{NS}$ \\
\hline
\end{tabular}

${ }^{1}$ BPT = MAX RB 392 power tier

${ }^{2} \mathrm{BPT}+\mathrm{E}=\mathrm{MAX} \mathrm{RB} 392$ power tier plus adjustable extension

${ }^{3} \mathrm{NS}=$ Not significant. 
Table 4

Comparison of Mean Wrist Acceleration by Rebar Tying Method (Chi Square Difference of Least Squares Means)

\begin{tabular}{lrrr} 
Plane & Pliers vs. BPT $^{1}$ & Pliers vs. BPT+E & $\begin{array}{r}\text { BPT vs } \\
\text { BPT+E }\end{array}$ \\
\hline Flexion/Extension & $<0.001$ & 0.001 & NS \\
\hline Ulnar/Radial & $<0.05$ & 0.0009 & NS \\
\hline Supination/Pronation & $<0.0001$ & $<0.0001$ & NS \\
\hline
\end{tabular}

${ }^{1}$ BPT = MAX RB 392 power tier

${ }^{2} \mathrm{BPT}+\mathrm{E}=\mathrm{MAX}$ RB 392 power tier plus adjustable extension

${ }^{3} \mathrm{NS}=$ Not significant. 
Table 5

Participants ( $n=5)$ Self Reported Ratings of Perceived Effort ${ }^{1}$ during Rebar Tying

\begin{tabular}{|l|c|c|c|}
\hline Perceived Effort & Pliers & Power Tier & Power Tier + Extension \\
\hline Hand-Wrist & 5.2 & 2.8 & 5.0 \\
\hline Low Back & 5.8 & 2.8 & 1.2 \\
\hline
\end{tabular}

${ }^{1}$ Borg 10 Point Perceived effort scale. ${ }^{2}$

Table 6

ACGIH Hand-Activity Level (HAL) ${ }^{6}$ Scores $^{a}$ for Mean Hand-Wrist Effort

Tying Rebar Using Pliers, BPT \& BPT+E

\begin{tabular}{|l|c|c|c|}
\hline Effort $^{\mathrm{b}}$ & Pliers & BPT & BPT+E \\
\hline Mean & $2.5^{\mathrm{c}}$ & $0.5^{\mathrm{d}}$ & $0.8^{\mathrm{c}}$ \\
\hline Low & $1.0^{\mathrm{c}}$ & $0.3^{\mathrm{d}}$ & $0.3^{\mathrm{d}}$ \\
\hline High & $3.5^{\mathrm{c}}$ & $1.0^{\mathrm{c}}$ & $1.2^{\mathrm{c}}$ \\
\hline
\end{tabular}

${ }^{a}$ Scores $<0.56$ are acceptable; scores $\geq 0.56$ and $\leq 0.77$ are at the action level; and scores $\geq 0.78$ exceed the TLV.

${ }^{\mathrm{b}}$ Participants' (n=5) response (mean, low \& high) on Borg 10 point perceived effort questionnaire.

${ }^{\mathrm{c}} \geq \mathrm{TLV}$.

d $<$ TLV 
Table 7

Time (seconds) ${ }^{a}$ in Trunk Postures during Rebar Tying

\begin{tabular}{|c|c|c|c|c|c|c|}
\hline Treatment & Posture & Mean (sec) & \% Time & $\mathrm{SD}$ & Min & Max \\
\hline \multirow[t]{7}{*}{$\mathrm{BPT}+\mathrm{E}$} & Neutral & $124^{b}$ & 83 & 35 & 55 & 150 \\
\hline & $16-30$ & $24^{c}$ & 16 & 36 & 0 & 95 \\
\hline & $31-45$ & 1 & $<1$ & 3 & 0 & 8 \\
\hline & $46-60$ & $<1$ & $<1$ & $<1$ & 0 & 1 \\
\hline & $61-75$ & $<1$ & $<1$ & $<1$ & 0 & $<1$ \\
\hline & $76-90$ & 0 & 0 & 0 & 0 & 0 \\
\hline & $>90$ & 0 & 0 & 0 & 0 & 0 \\
\hline \multirow[t]{7}{*}{ BPT } & Neutral & $<1$ & $<1$ & 1 & 0 & 2 \\
\hline & $16-30$ & $<1$ & $<1$ & $<1$ & 0 & $<1$ \\
\hline & $31-45$ & $<1$ & $<1$ & $<1$ & 0 & $<1$ \\
\hline & $46-60$ & $<1$ & $<1$ & $<1$ & 0 & $<1$ \\
\hline & $61-75$ & $<1$ & $<1$ & $<1$ & 0 & 1 \\
\hline & $76-90$ & $5^{c}$ & 3 & 7 & 0 & 18 \\
\hline & $>90$ & $140^{b}$ & 93 & 13 & 110 & 150 \\
\hline \multirow[t]{7}{*}{ Pliers } & Neutral & 0 & 0 & 0 & 0 & 0 \\
\hline & $16-30$ & 0 & 0 & 0 & 0 & 0 \\
\hline & $31-45$ & 0 & 0 & 0 & 0 & 0 \\
\hline & $46-60$ & $<1$ & $<1$ & $<1$ & $<1$ & 1 \\
\hline & $61-75$ & $<1$ & $<1$ & 1 & 0 & 2 \\
\hline & $76-90$ & $6^{c}$ & 4 & 7 & 1 & 23 \\
\hline & $>90$ & $141^{\mathrm{b}}$ & 93 & 9 & 126 & 150 \\
\hline
\end{tabular}

${ }^{\text {a }}$ Total sample time $=150$ seconds

${ }^{\mathrm{b}} \mathrm{p}<0.0001$ (Comparing differences between BPT $+\mathrm{BPT}+\mathrm{E}$ and pliers $+\mathrm{BPT}+\mathrm{E}$ )

${ }^{c} \mathrm{p}<0.05$ (Comparing differences between BPT + BPT $+E$ and pliers + BPT+E)

Table 8

Percent Time Free Arm Used to Supported Trunk during Extreme Flexion Using Power Rebar Tier per Participant

\begin{tabular}{lcccccccc} 
& P1 & P2 & P3 & P4 & P5 & P6 & P7 & P8 \\
\hline Supported $^{\mathrm{a}}$ & $94.9 \%$ & $91.0 \%$ & $92.3 \%$ & $89.5 \%$ & $86.4 \%$ & $98.3 \%$ & $96.6 \%$ & $90.0 \%$ \\
\hline Unsupported $^{5.1 \%}$ & $9.0 \%$ & $7.7 \%$ & $10.5 \%$ & $13.6 \%$ & $1.7 \%$ & $3.4 \%$ & $10.0 \%$ \\
\hline
\end{tabular}

${ }^{a}$ Ironworkers used the free hand or forearm to support an unknown proportion of their head/trunk weight. 
Table 9

Estimated Forces on the L5/S1 Disc Using the 3D SSPP

\begin{tabular}{|c|c|c|c|c|}
\hline & Trunk & Angle & $\begin{array}{c}\text { Total } \\
\text { Compression }\end{array}$ & $\begin{array}{l}\text { Total } \\
\text { Shear }\end{array}$ \\
\hline & $\begin{array}{r}\text { Flexion } \\
\text { Rotation } \\
\text { Lateral }\end{array}$ & $\begin{array}{r}-90^{\circ} \\
0^{\circ} \\
0^{\circ}\end{array}$ & $2427 \mathrm{~N}$ & $389 \mathrm{~N}$ \\
\hline & $\begin{array}{c}\text { Flexion } \\
\text { Rotation } \\
\text { Lateral }\end{array}$ & $\begin{array}{r}-90^{\circ} \\
0^{\circ} \\
+/- \\
25^{\circ}\end{array}$ & $2857 \mathrm{~N}$ & $306 \mathrm{~N}$ \\
\hline & $\begin{array}{r}\text { Flexion } \\
\text { Rotation } \\
\text { Lateral }\end{array}$ & $\begin{array}{r}-105^{\circ} \\
0^{\circ} \\
0^{\circ}\end{array}$ & $1864 \mathrm{~N}$ & $419 \mathrm{~N}$ \\
\hline & $\begin{array}{r}\text { Flexion } \\
\text { Rotation } \\
\text { Lateral }\end{array}$ & $\begin{array}{r}-105^{\circ} \\
0^{\circ} \\
+/- \\
25^{\circ}\end{array}$ & $2322 \mathrm{~N}$ & $480 \mathrm{~N}$ \\
\hline & $\begin{array}{r}\text { Flexion } \\
\text { Rotation } \\
\text { Lateral } \\
\end{array}$ & $\begin{array}{r}-115^{\circ} \\
0^{\circ} \\
0^{\circ} \\
\end{array}$ & $1511 \mathrm{~N}$ & $401 \mathrm{~N}$ \\
\hline & $\begin{array}{r}\text { Flexion } \\
\text { Rotation } \\
\text { Lateral }\end{array}$ & $\begin{array}{r}-115^{\circ} \\
0^{\circ} \\
+/- \\
25^{\circ}\end{array}$ & $1930 \mathrm{~N}$ & $501 \mathrm{~N}$ \\
\hline
\end{tabular}


Table 10

Estimated ${ }^{a}$ Cumulative Physical Workload $\left(\mathrm{N}-\mathrm{h}^{\mathrm{b}}\right)$ on the Low Back (L5/S1)

Due to Extreme Forward Flexion after 1, 5, and 10 Years

\begin{tabular}{lcccccrr} 
Flexion & Newtons & Hrs/Day & Days/Wk & $\mathbf{W k} / \mathbf{Y r}$ & $\mathbf{N}-\mathbf{h} / \mathbf{1} \mathbf{~ Y r}$ & $\mathbf{N}-\mathbf{h} / \mathbf{5} \mathbf{~ Y r}$ & $\mathbf{N}-\mathbf{h} / \mathbf{1 0} \mathbf{~ Y r}$ \\
\hline $90 \mathrm{deg}$ & 2642 & 2 & 5 & 36 & $0.9 \mathrm{E}+06$ & $4.8 \mathrm{E}+06$ & $9.5 \mathrm{E}+06$ \\
& & 4 & 5 & 36 & $1.9 \mathrm{E}+06$ & $9.5 \mathrm{E}+06$ & $19.0 \mathrm{E}+06$ \\
& & 6 & 5 & 36 & $2.9 \mathrm{E}+06$ & $14.0 \mathrm{E}+06$ & $29.0 \mathrm{E}+06$ \\
\hline $105 \operatorname{deg}$ & 2093 & 2 & 5 & 36 & $0.7 \mathrm{E}+06$ & $3.8 \mathrm{E}+06$ & $7.5 \mathrm{E}+06$ \\
& & 4 & 5 & 36 & $1.5 \mathrm{E}+06$ & $7.5 \mathrm{E}+06$ & $15.0 \mathrm{E}+06$ \\
& & 6 & 5 & 36 & $2.3 \mathrm{E}+06$ & $11.0 \mathrm{E}+06$ & $23.0 \mathrm{E}+06$ \\
\hline $115 \operatorname{deg}$ & 1721 & 2 & 5 & 36 & $0.6 \mathrm{E}+06$ & $3.1 \mathrm{E}+06$ & $6.2 \mathrm{E}+06$ \\
& & 4 & 5 & 36 & $1.2 \mathrm{E}+06$ & $6.2 \mathrm{E}+06$ & $12.0 \mathrm{E}+06$ \\
& & 6 & 5 & 36 & $1.9 \mathrm{E}+06$ & $9.3 \mathrm{E}+06$ & $19.0 \mathrm{E}+06$ \\
\hline
\end{tabular}

${ }^{a}$ Equation used to calculate annual load on L5/S1 shown in Figure $6 .{ }^{12}$

${ }^{\mathrm{b}} \mathrm{N}-\mathrm{h}=$ Newton-hours. 
Table 11

Number of Ties Completed in 2.5 Minutes by Treatment

\begin{tabular}{crrr} 
Subject & Pliers & BPT & BPT+E \\
\hline 1 & 47 & 85 & 55 \\
2 & 31 & 71 & 41 \\
3 & 44 & 89 & 54 \\
4 & 48 & 99 & 58 \\
5 & $36^{\mathrm{a}}$ & 69 & 53 \\
6 & 51 & 93 & 66 \\
7 & 37 & $79^{\mathrm{b}}$ & 38 \\
\hline Mean & 42 & 84 & 52 \\
\hline SD & 6.8 & 10.3 & 9.0 \\
\hline \multicolumn{2}{c}{ a Adjusted for 2'15” sample period. } \\
b Adjusted for 2'23” sample period.
\end{tabular}


DEPARTMENT OF HEALTH AND HUMAN SERVICES

Centers for Disease Control and Prevention

National Institute for Occupational Safety and Health

4676 Columbia Parkway

Cincinnati, OH 45226-1998

OFFICIAL BUSINESS

Penalty for private use $\$ 300$

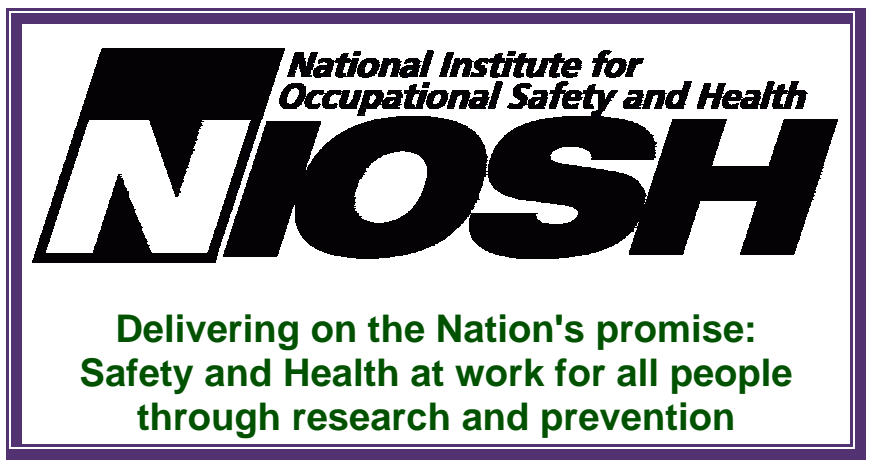

To receive NIOSH documents or information about occupational safety and health topics contact $\mathrm{NIOSH}$ at:

\section{1-800-35-NIOSH (356-4674)}

Fax: 1-513-533-8573

E-mail: pubstaft@cdc.gov

or visit the NIOSH web site at:

http://www.cdc.gov/niosh

S AFER • HEALTHIER • PEOPLE 